\title{
Immunosuppressive effect of sinomenine in an allergic rhinitis mouse model
}

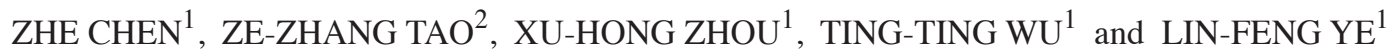 \\ ${ }^{1}$ Department of Otolaryngology Head and Neck Surgery, Zhongnan Hospital of Wuhan University, \\ Wuhan, Hubei 430072; ${ }^{2}$ Department of Otolaryngology Head and Neck Surgery, \\ Renmin Hospital of Wuhan University, Wuhan, Hubei 430060, P.R. China
}

Received March 30, 2016; Accepted November 25, 2016

DOI: $10.3892 /$ etm.2017.4237

\begin{abstract}
Allergic rhinitis (AR) is a chronic allergic airway disease that has become a significant global public health issue. Sinomenine (SN), a natural phytochemical found in Sinomenium acutum, showed anti-inflammatory and immunosuppressive effect in previous studies. In order to explore the role of $\mathrm{SN}$ in the treatment of $\mathrm{AR}$, mice were sensitized and challenged by ovalbumin (OVA) to establish an AR mouse model. SN was administered to AR mice orally, and compared with dexamethasone treatment as a positive control. Nasal symptoms and histopathological changes were used to evaluate the effect of SN treatment in the AR mice model. In addition, the levels of anti-OVA specific IgE and various cytokines in the serum were measured by enzyme-linked immunosorbent assay, while the levels of transforming growth factor- $\beta$ (TGF- $\beta$ ) in the mucosa were also detected by western blot analysis and reverse transcription-quantitative polymerase chain reaction. AR mice that received $\mathrm{SN}$ treatment had reduced symptom scores and milder eosinophil infiltration. The serum levels of anti-OVA specific IgE and interleukin-4 significantly decreased following SN treatment. Furthermore, TGF- $\beta$ expression levels in the serum and nasal mucosa tissue in AR mice increased when compared with those in AR mice without treatment. In conclusion, $\mathrm{SN}$ treatment alleviated the symptoms of AR in mice and had an immunosuppressive effect on AR, which may result from the upregulation of TGF- $\beta$.
\end{abstract}

\section{Introduction}

Allergic rhinitis (AR) is a chronic, reversible allergic airway disease that has become a significant global public health concern and >500 million people around the world are

Correspondence to: Dr Zhe Chen, Department of Otolaryngology Head and Neck Surgery, Zhongnan Hospital of Wuhan University, 169 Donghu Road, Wuhan, Hubei 430072, P.R. China

E-mail:wb002987@whu.edu.cn

Key words: $\mathrm{BALB} / \mathrm{c}$ mouse, allergic rhinitis, sinomenine, immunosuppression, transforming growth factor- $\beta$ estimated to currently be suffering with AR (1). Symptoms of AR include rhinorrhoea, nasal obstruction, nasal itching and sneezing, and it is often associated with ocular symptoms. Impairment of quality-of-life is observed in the majority of patients. They may suffer from sleep disorders and emotional problems, and experience impairments in completing activities and proper social functioning.

AR is a Type I allergic disease caused by an immunoglobulin $\mathrm{E}$ ( $\mathrm{IgE}$ )-mediated adaptive immune response. IgE production results from complex interactions between B cells, $\mathrm{T}$ cells, mast cells and basophils, and involves the presence of interleukin (IL)-4, IL-13 and IL-18 cytokines, as well as a physical interaction between $\mathrm{T}$ and $\mathrm{B}$-cells by a number of surface and adhesion molecules (2). T-helper 2 (Th2) cells (3) and a downregulation of T-regulatory cell responses (4-6) drive the synthesis of $\operatorname{IgE}$ and the recruitment, maturation, survival and effector function of accessory cells, such as eosinophils, basophils and mast cells. The influx of eosinophils and Th2 cells, producing IL-4, IL-5 and IL-13, is the main feature of AR (7).

Chinese traditional herbal medicines have long been used to maintain the immune balance and to treat various allergic diseases, such as allergic rhinitis (8-11), asthma (12) and atopic dermatitis (13). Biminne is the first herbal preparation to be clinically tested for AR internationally. It has anti-allergic and anti-inflammatory effects not only through its ability to restrain inflammatory cells degranulation and antagonistic inflammatory medium, but it can also reduce and remove serum $\mathrm{IgE}$ levels (8). Herbal formulas in traditional Chinese medicine referred to as Yu-ping-feng-san (9), Bu-zhong-yi-qi-tang (10) and Xin-yi-san (11) are also considered to be effective medicines for allergic rhinitis treatment. There is little research focus on the isolation of herbal in allergic rhinitis. Sinomenine (SN) was first isolated from Sinomenium acutum in the 1920 's (14), and since then a vast number of pharmacological and clinical studies have been performed in China and Japan, demonstrating that the pure alkaloid extract of SN possesses anti-inflammatory and immune-regulatory properties $(14,15)$. Therefore, it is hypothesized that SN may be capable of immune-modulatory effects on the allergic inflammation of the airways. The aim of the present study was to evaluate whether SN had an effect on inflammation of the nasal mucosa, as well as on the immune response in an AR mouse model. 


\section{Materials and methods}

Animals. A total of 40 male BALB/c mice (5-week-old; $16-18 \mathrm{~g}$ ) raised and maintained under specific pathogen-free conditions were obtained from the Hubei Center for Disease Control and Prevention (Wuhan, China). All mice were maintained under standard conventional conditions: 12-h light/dark cycle, temperature $\left(18-22^{\circ} \mathrm{C}\right)$ and humidity $(50-60 \%)$, with food and water ad libitum. The animals were randomly divided into four groups: Normal group, AR group, SN group and dexamethasone (Dex) group and each group consisted of 10 mice. Corticosteroids such as dexamethasone, the most potent therapeutic agents used for allergic rhinitis, profoundly inhibit the activity of $\mathrm{T}$ cells largely through the inhibition of expression of various cytokines $(1,16)$, thus we make it as a positive control. Mice in the AR, SN and Dex groups were sensitized by intraperitoneal injection with $500 \mu 1$ phosphate-buffered saline (PBS) containing $10 \mu \mathrm{g}$ ovalbumin (OVA; grade V; Sigma-Aldrich; Merck Millipore, Darmstadt, Germany) and $1 \mathrm{mg}$ aluminum hydroxide on days 0,7 and 14 . Mice in the AR, SN and Dex groups were subjected to intranasal challenge with $20 \mu \mathrm{l}$ PBS containing $500 \mu \mathrm{g}$ OVA for 7 days, between days 21 and 27 (17). Mice in the normal group were injected with PBS alone, and PBS was administered intranasally following the same schedule. Along with sensitization and challenge, selected groups of mice were administered $100 \mathrm{mg} / \mathrm{kg} \mathrm{SN}$ (purity, $\geq 98 \%$ ) or $2 \mathrm{mg} / \mathrm{kg}$ Dex (purity, $\geq 98 \%$; both Sigma-Aldrich; Merck Millipore), which were dissolved in $200 \mu 1$ PBS and orally administered daily $2 \mathrm{~h}$ before intranasal OVA challenge between days 21 and 27 (18). The experimental protocol is shown in more detail in Fig. 1. The protocols of the current study were approved by the Animal Ethics Committee of Renmin Hospital of Wuhan University (Wuhan, China).

Measurement of nasal symptoms and tissue preparation. At 20 min after the final OVA/PBS challenge on day 27, four observers blinded to the study groups recorded the frequencies of nasal rubbing and sneezing in each group. After $24 \mathrm{~h}$ from the last challenge with OVA/PBS, mice were anesthetized with 1-2 ml diethyl ether (60-29-7; Sinopharm Chemical Reagent Co., Ltd., Shanghai, China) volatilized in a 2 liter seal pot. Blood was drawn blood from the eyeballs and mice were sacrificed quickly by cervical dislocation. The nasal mucosa of mice was rapidly collected once the mice were sacrificed using a small curette under a microscope meticulously and was immediately immersed in liquid nitrogen and stored until further use in reverse transcription-quantitative polymerase chain reaction (RT-qPCR) and western blot analyses.

Histopathological evaluation of nasal cavity. Nasal tissues were removed $24 \mathrm{~h}$ after the last challenge with OVA/PBS, fixed in $10 \%$ neutral buffered formalin and decalcified. The coronal nasal section $(5 \mu \mathrm{m})$ was stained with hematoxylin and eosin, and the number of eosinophils was counted under a microscope at four random high-power fields (HPFs) of the submucosal region of the nasal cavity at $\mathrm{x} 400$ magnification (19), then the mean was taken as the number of eosinophils in each group.

Enzyme-linked immunosorbent assay (ELISA). Mice serum was obtained immediately after sacrifice, and stored at $4^{\circ} \mathrm{C}$. Serum levels of anti-OVA specific IgE (N509; R\&D Systems, Inc., Minneapolis, MN, USA), interferon- $\gamma$ (IFN- $\gamma$; BMS6027), IL-4 (BMS613) and transforming growth factor- $\beta$ (TGF- $\beta$; BMS608/4; eBioscience, Inc., San Diego, CA, USA) in the animals were measured using commercially available ELISA kits, according to the manufacturer's recommendations. The concentrations of anti-OVA specific IgE, IFN- $\gamma$, IL- 4 and TGF- $\beta$ were calculated from the equations obtained from standard curve plots for the standard solutions in the kits.

$R T-q P C R$. TotalRNA was prepared from the nasal mucosa of the mice using TRIzol reagent (N15596-026, Invitrogen; Thermo Fisher Scientific, Inc., Waltham, MA, USA). Complementary DNA (cDNA) was synthesized from $2 \mu \mathrm{g}$ total RNA using Superscript Reverse Transcriptase and oligo (dT) primers (K1629; Fermentas; Thermo Fisher Scientific, Inc.). For the analysis of TGF- $\beta$ and GAPDH levels, specifically-designed primers and probes were purchased from Invitrogen (Thermo Fisher Scientific, Inc.). The mRNA expression of TGF- $\beta$ and GAPDH was determined by qPCR, through amplifying $25 \mathrm{ng}$ cDNA in $50 \mu 1$ 1X SYBR-Green PCR Master Mix (DRR041A, Takara Biotechnology Co., Ltd., Dalian, China) containing $200 \mathrm{nM}$ primers. qPCR primers were as follows: TGF- $\beta$ forward, 5'-AGGGCTACCATGCCAACTTC-3' and reverse, 5'-CCACGTAGTAGACGATGGGC-3'; and GAPDH forward, 5'-ACCCAGAAGACTGTGGATGG-3' and reverse, 5'-TGC TGTAGCCAAATTCGTTG-3'. Experiments were performed in triplicate, using an ABI Prism 7500 Sequence Detection system (Applied Biosystems; Thermo Fisher Scientific, Inc.). The average transcript levels of genes were then normalized to GAPDH. Negative controls (Master Mix containing untranscribed total RNA, or sample without any cDNA or RNA) were used in each experiment. Relative quantitation of TGF- $\beta$ mRNA expression was calculated as the fold increase in expression using the $2^{-\Delta \Delta \mathrm{Cq}}$ method (20) and the housekeeping gene was GAPDH.

Western blot analysis. Proteins were obtained from the nasal mucosa of each group using lysis buffer (containing $0.5 \%$ Triton $\mathrm{X}-100,150 \mathrm{mM} \mathrm{NaCl}, 15 \mathrm{mM}$ Tris (pH 7.4) $1 \mathrm{mM} \mathrm{CaCl}_{2}$ and $1 \mathrm{mM} \mathrm{MgCl} 2$ ). The protein concentrations were determined using a BCA protein assay reagent (Thermo Fisher Scientific, Inc.). Samples $(20 \mu \mathrm{l} ; 2.7 \mu \mathrm{g} / \mathrm{ml})$ were separated by $12 \%$ SDS-PAGE and transferred onto polyvinylidene difluoride membranes (EMD Millipore, Billerica, MA, USA). Next, the samples were immunoblotted with primary antibodies against TGF- $\beta$ (3711) and GAPDH (5174; Cell Signaling Technology, Inc., Danvers, MA, USA) at $4^{\circ} \mathrm{C}$ overnight. Following washing with 1X TBST solution, membranes were immunoblotted with secondary antibodies (7074; Cell Signaling Technology, Inc.) at room temperature for $1 \mathrm{~h}$. Proteins were subsequently detected with an enhanced chemiluminescence reagent (P0018; Beyotime Institute of Biotechnology, Shanghai, China) and transferred to X-ray films. Finally, Quantity One software (version 4.6.2; Bio-Rad Laboratories, Inc., Hercules, CA, USA) was used to quantify the results.

Statistical analysis. The results are presented as the mean \pm standard error of the mean. A Mann-Whitney U-test was used to compare results between different groups. 


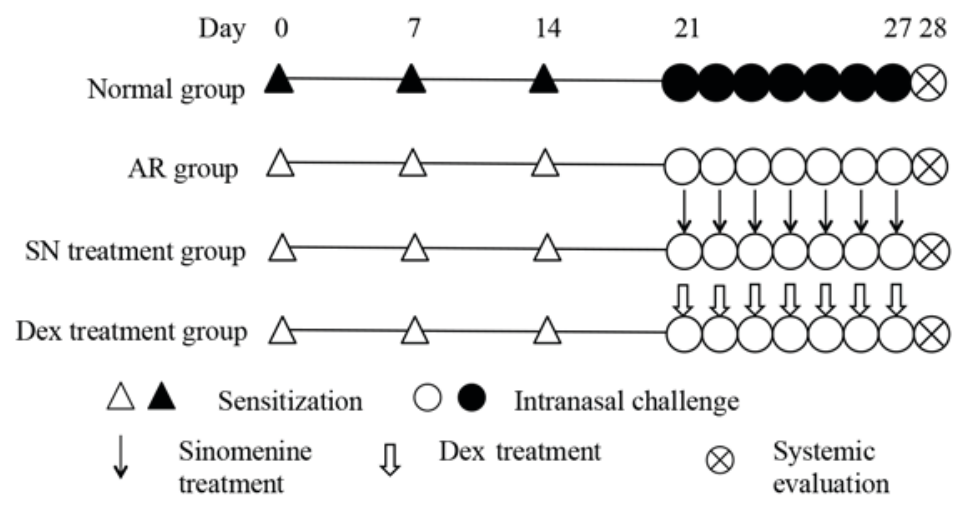

Figure 1. Experimental protocol of the present study. Mice were sensitized with OVA and aluminum hydroxide on days 0,7 and 14 . All groups except for the normal group received intranasal OVA between days 21 and 27. Selected groups of mice were also treated with intraperitoneal injection of the SN or Dex at $2 \mathrm{~h}$ before intranasal OVA challenge. OVA, ovalbumin; AR, allergic rhinitis; SN, sinomenine; Dex, dexamethasone.

Statistical analyses were performed by the SPSS statistical software (version 16.0; SPSS, Inc., Chicago, IL, USA). P-values of $<0.05$ were considered as indicating statistically significant associations.

\section{Results}

Symptom scoring. The nasal rubbing and sneezing symptom scores in the AR group were significantly elevated when compared with those in the normal group. The frequencies were $8.6 \pm 1.2$ and $5.8 \pm 1.7$ times/20 min in the AR group, respectively. By contrast, the scores were significantly lower in the two treatment groups when compared with the untreated AR group (Nasal rubbing: $\mathrm{AR}$ vs. $\mathrm{AR}+\mathrm{SN}, \mathrm{P}=0.0218$; $\mathrm{AR}$ vs. $\mathrm{AR}+\mathrm{Dex}, \mathrm{P}=0.0091$; Sneezing: AR vs. $\mathrm{AR}+\mathrm{SN}, \mathrm{P}=0.0054$; $A R$ vs. $A R+D e x, P=0.0055 ; P<0.05)$, and the $S N$ treatment group showed no significant decrease in symptom incidence compared with the Dex treatment group (Fig. 2).

Histology of nasal mucosa and eosinophil infiltration. Histological images of the nasal tissue of each group are shown in Fig. 3. These images demonstrated decreased eosinophil infiltration and decreased epithelial layer disruption in the SN and Dex treatment groups when compared with the AR group (Fig. 3). The eosinophil count per HPF in the AR group was $31.5 \pm 4.9$, which was significantly higher from that of the normal group $(2.8 \pm 0.9$ eosinophils/HPF; $\mathrm{P}<0.05)$. The eosinophil counts per HPF in the SN treatment group and Dex treatment group were $18.5 \pm 4.5$ and $20.3 \pm 5.7$, respectively (Fig. 4); thus, the number of eosinophils was significantly reduced in the two treatment groups $(\mathrm{P}<0.05)$ when compared with the AR group. These results indicate that the SN and Dex treatments decreased the eosinophil migration in the nasal mucosa, but there was no significant difference between them $(\mathrm{P}>0.05)$.

Serum levels of OVA-specific IgE and cytokines. In order to evaluate the effects of the SN treatment on AR, the serum levels of OVA-specific IgE and various cytokines were detected by ELISA. The results indicated that OVA-specific IgE levels significantly decreased in the two treatment groups when compared with those in the AR group $(\mathrm{P}<0.05$; Fig. 5).
The $\mathrm{SN}$ treatment group demonstrated a significant decrease $(\mathrm{P}<0.05)$ in the Th2 cytokine IL-4 level in comparison with the level in the AR group, which was consistent with the observed symptom scores and histological observations. Similarly, the Th1 cytokine IFN- $\gamma$ was also significantly reduced $(\mathrm{P}<0.05)$ in the two treatment groups (Fig. 5). Furthermore, treatment with SN resulted in enhancement of the production of TGF- $\beta$ in the mouse serum (Fig. 6A).

Expression of TGF- $\beta$ in the nasal mucosa. The level of TGF- $\beta$ transcriptional activity was evaluated in the nasal mucosa of each group by RT-qPCR (Fig. 6B). The mRNA expression levels of TGF- $\beta$ were significantly increased in the SN treatment group when compared with the AR group $(\mathrm{P}<0.05)$. Furthermore, the protein levels of TGF- $\beta$ in the nasal mucosa were also significantly elevated in the $\mathrm{SN}$ treatment group, as determined by western blot analysis (Fig. 6C and D). The expression of TGF- $\beta$ in the Dex group exhibited almost the same change when compared to the AR group.

\section{Discussion}

The majority of the clinical symptoms of AR, including rhinorrhea, nasal itching, sneezing and nasal congestion, cause significant discomfort to patients (21). AR is considered to result from an IgE-mediated allergy associated with a nasal inflammation of variable intensity (1). Cells, mediators, cytokines, chemokines, neuropeptides, as well as adhesion molecules and cells (2-7,22-25), are all considered to cooperate in a complex network, provoking specific symptoms and nonspecific nasal hyperreactivity. IgE production is induced following complex interactions between B-cells, T-cells, mast cells and basophils, and involves the presence IL-4, IL-13 and IL-18 cytokines and a physical interaction between $\mathrm{T}$ and $\mathrm{B}$-cells by various surface and adhesion molecules (2). Eosinophils numbers are increased and activated in the nasal mucosa of patients with symptomatic allergic (22). Various mediators are released in nasal secretions, such as CysLT (23), ECP (24) and histamine (25). CD4 $4^{+}$lymphocytes with a Th2 phenotype serve an important role in the development of AR, and the suppression of Th2 lymphocytes may be a potential therapeutic target for the treatment of AR. 

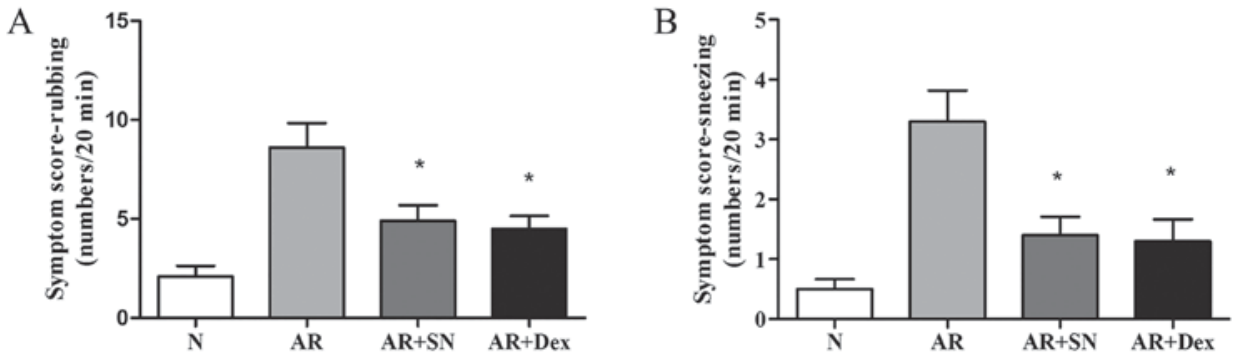

Figure 2. Systemic treatment with SN suppressed allergic symptoms. (A) Rubbing symptom score. (B) Sneezing symptom score. "P<0.05, vs. AR group. $\mathrm{N}$, normal; AR, allergic rhinitis; SN, sinomenine; Dex, dexamethasone.
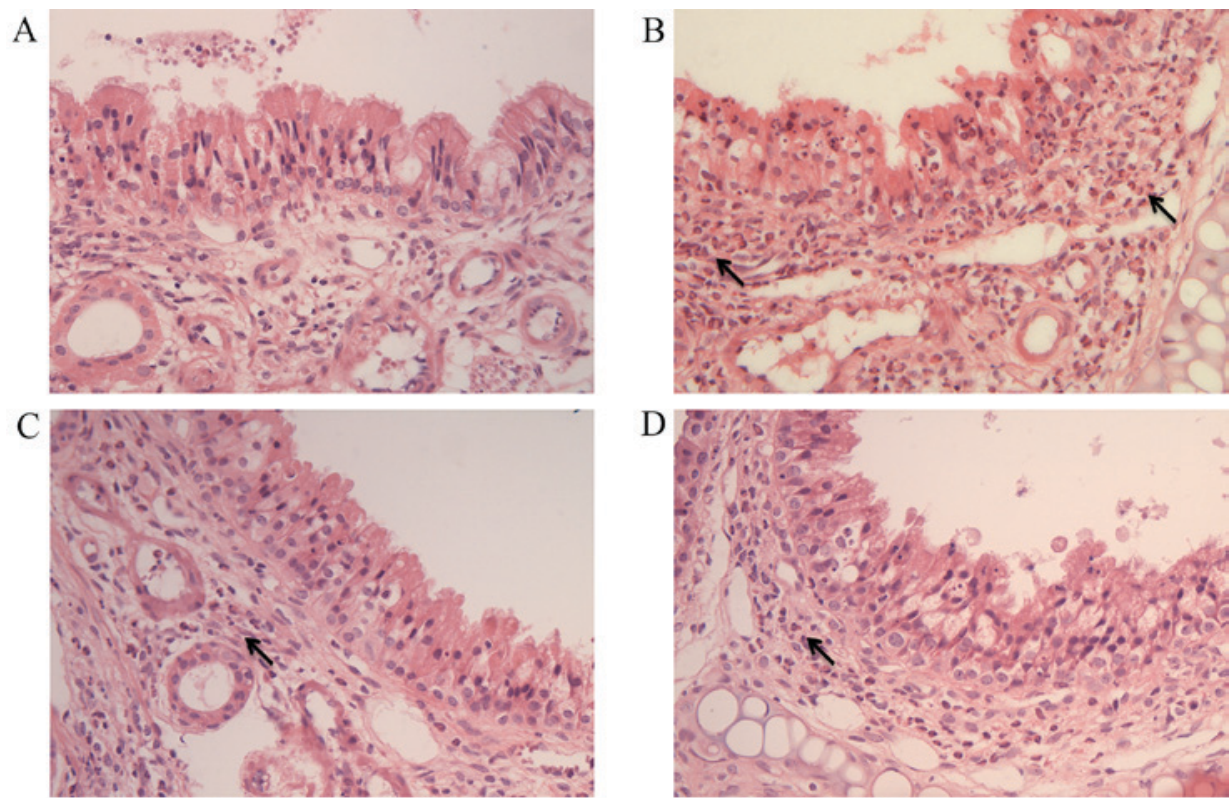

Figure 3. Histological analysis of nasal mucosa in the (A) normal, (B) AR, (C) AR+SN and (D) AR+Dex groups. Systemic treatment with SN suppressed the eosinophil infiltration in the nasal mucosa (magnification, $\mathrm{x} 400$ ). The normal group showed no inflammatory changes, while the nasal mucosa was infiltrated with eosinophils in the AR group (arrow). Eosinophilic infiltration was markedly reduced in the SN and Dex treatment groups. AR, allergic rhinitis; SN, sinomenine; Dex, dexamethasone.

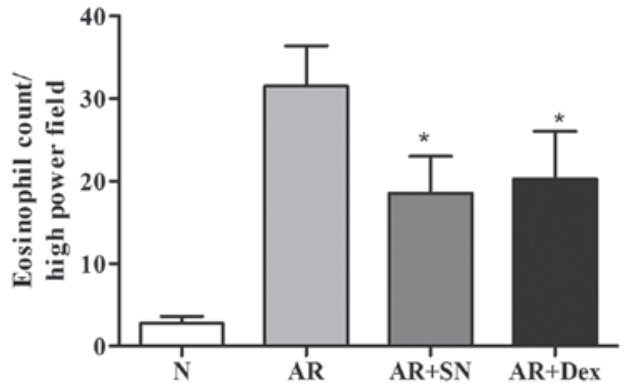

Figure 4. Number of eosinophils in the nasal mucosa. The number of eosinophils was significantly reduced in the SN and Dex treatment group when compared with that in the AR group. " $\mathrm{P}<0.05$ vs. the AR group. N, normal; AR, allergic rhinitis; SN, sinomenine; Dex, dexamethasone.

Various Chinese traditional medicine formulas have been used for the treatment of allergic diseases for thousands of years. The search for appropriate natural products may provide further treatment options for allergic diseases to the currently used drugs. In vitro studies have demonstrated that $\mathrm{SN}$ is able to inhibit lymphocyte proliferation and antibody production by B cells, as well as to potently reduce the production of inflammatory factors by macrophages (26-28). SN also inhibits the antigen-presenting capacity of bone marrow-derived DCs with the decrease of IL- 12 , TNF- $\alpha$ and IL- $1 \beta$ production (29). In addition, $\mathrm{SN}$ affects the production of several allergic mediators, including IL-6, PGD2, LTC4, $\beta$-Hex and COX-2 protein (30). In vitro experiments by Shu et al (31). revealed that the immunosuppressive activity elicited by $\mathrm{SN}$ in $\mathrm{CD}^{+}$primary lymphocytes was largely attributed to caspase-3-dependent apoptosis These findings indicate that $\mathrm{SN}$ has the potential for use in the treatment of allergies.

In the present study, AR mice treated with SN or Dex had lower symptoms scores for nose rubbing and sneezing. Meanwhile, the infiltration of eosinophils, the proliferation of goblet cells and the loss of ciliated cells in the nasal epithelium are common histopathological changes of the nasal mucosa in AR mice (32). Subsequent to treatment with SN or Dex, the number of eosinophils was reduced when compared with that in the nasal mucosa of untreated AR mice. Thus, it can be concluded that SN treatment, as well as Dex treatment, decreased changes in the nasal mucosa and alleviated the symptoms in AR mice. 

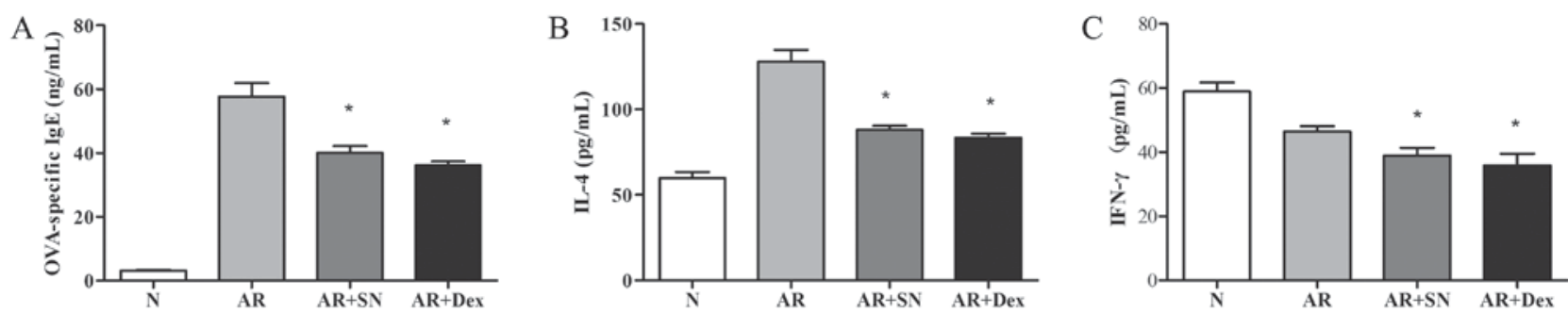

Figure 5. Protein levels of (A) OVA-specific IgE, (B) IL-4 and (C) IFN- $\gamma$ in the various study groups, as determined by ELISA. Systemic treatment with SN suppressed OVA-specific IgE, while the levels of systemic Th 2 cytokine IL- 4 and Th1 cytokine IFN- $\gamma$ decreased subsequent to SN administration. " $\mathrm{P}<0.05$ vs. the AR group. OVA, ovalbumin; IL-4, interleukin-4; IFN, interferon; N, normal; AR, allergic rhinitis; SN, sinomenine; Dex, dexamethasone.

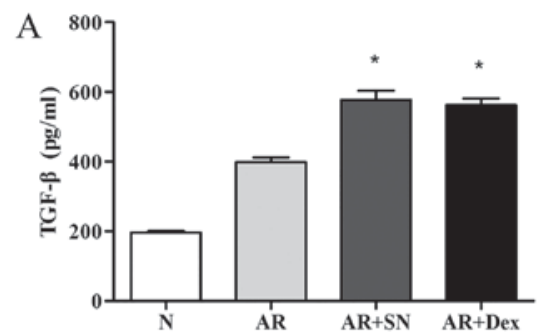

$\mathrm{C}$

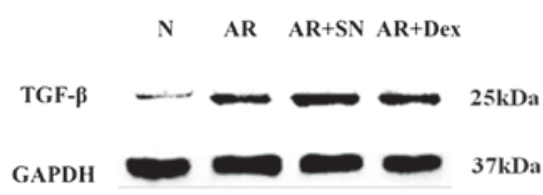

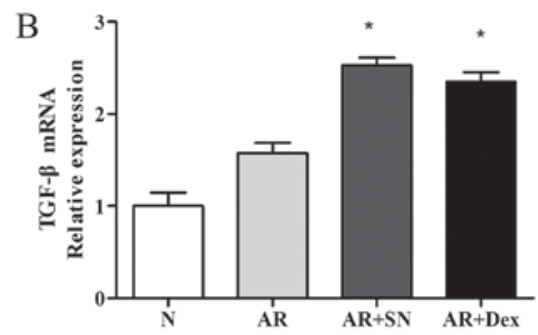

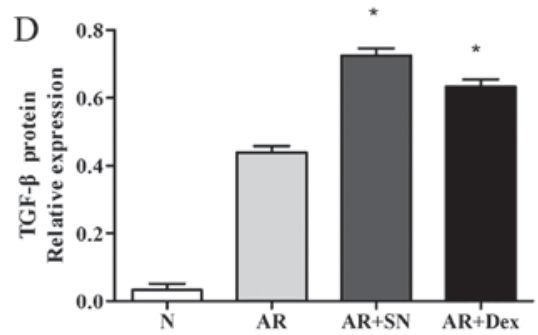

Figure 6. Systemic treatment with SN significantly increased the expression of TGF- $\beta$. (A) Expression of TGF- $\beta$ in the mouse serum as determined by ELISA. (B) mRNA expression levels of TGF- $\beta$ in the nasal mucosa, as determined by reverse transcription-quantitative polymerase chain reaction. (C) Western blot and (D) quantified results of protein levels of TGF- $\beta$ in the nasal mucosa. "P<0.05 vs. the AR group. TGF, transforming growth factor; N, normal; AR, allergic rhinitis; SN, sinomenine; Dex, dexamethasone.

OVA-specific IgE and IL-4 levels were found to increase in AR mice compared with those in the normal group. However, SN significantly inhibited the expression of OVA-specific IgE and IL-4 in AR mice in the current study experiments. Similarly, Feng et al (18) observed that SN treatment suppressed the production of antibodies, including anti-OVA $\operatorname{IgG} 2 \mathrm{a}, \operatorname{IgG} 1$ and $\mathrm{IgE}$, as well as the secretion of cytokines, such as IFN- $\gamma$ and IL-5. In addition, this previous study demonstrated that SN enhanced the secretion of TGF- $\beta$ (18). $\mathrm{SN}$ also serves an important role in the Th1/Th2 cell balance by regulating the expression levels of T-bet and GATA-3, which are the transcription factors of Th1 and Th2, respectively (33). All these aforementioned results suggest that SN appears to have a suppressive effect on AR. The regulatory $\mathrm{T}$ cells (Tregs) have been shown to suppress Th1 and Th2 responses in vitro (34-36), and TGF- $\beta$ was considered to serve an important role in the development and differentiation of Tregs (37-39). In the present study, treatment with SN was followed by an enhancement of TGF- $\beta$ secretion. Thus, the downregulation of $\mathrm{Th} 2$ responses and allergic symptom scores by $\mathrm{SN}$ treatment may be associated with the role of this Treg cytokine in these immune responses.

In conclusion, the present study demonstrated that SN had an inhibitory efficacy on AR, by alleviating the symptoms and inhibiting the expression of OVA-specific IgE and Th2 cytokines in OVA-induced AR mice. SN treatment also reduced the eosinophil infiltration. These results may depend on the induction of the local and systemic TGF- $\beta$ expression, which is an important cytokine in Treg cells, by SN treatment. Therefore, the results suggest that $\mathrm{SN}$ may have a good potency in AR treatment.

\section{Acknowledgements}

The authors are grateful to the staff in the laboratory of Renmin Hospital of Wuhan University (Wuhan, China) who fully cooperated and provided important support to the current project. The authors would specifically like to thank Dr Liu Ying (College Of Nursing, The Second Military Medical University, Shanghai, China) for correcting the manuscript.

\section{References}

1. Bousquet J, Khaltaev N, Cruz AA, Denburg J, Fokkens WJ, Togias A, Zuberbier T, Baena-Cagnani CE, Canonica GW, van Weel C, et al: Allergic rhinitis and its impact on asthma (ARIA) 2008 update (in collaboration with the World Health Organization, GA(2)LEN and AllerGen). Allergy 63 (Suppl 86): S8-S160, 2008. 
2. Punnonen J, Aversa GG, Vandekerckhove B, Roncarolo MG and de Vries JE: Induction of isotype switching and Ig production by $\mathrm{CD}^{+}$and $\mathrm{CD}^{+} 0^{+}$human fetal B cells. J Immunol 148: 3398-3404, 1992.

3. Romagnani S: Immunologic influences on allergy and the TH1/TH2 balance. J Allergy Clin Immunol 113: 395-400, 2004.

4. Romagnani S: Regulatory T cells: Which role in the pathogenesis and treatment of allergic disorders? Allergy 61: 3-14, 2006.

5. Allam JP and Novak N: Immunological mechanisms of sublingual immunotherapy. Curr Opin Allergy Clin Immunol 14: 564-569, 2014.

6. Akdis CA, Barlan IB, Bahceciler N and Akdis M: Immunological mechanisms of sublingual immunotherapy. Allergy 61 (Suppl 81): S11-S14, 2006

7. Wilson MS, Taylor MD, Balic A, Finney CA, Lamb JR and Maizels RM: Suppression of allergic airway inflammation by helminth-induced regulatory T cells. J Exp Med 202: 1199-1212, 2005.

8. Hu G, Walls RS, Bass D, Ramon B, Grayson D, Jones M and Gebski V: The Chinese herbal formulation biminne in management of perennial allergic rhinitis: A randomized, double-blind, placebo-controlled, 12-week clinical trial. Ann Allergy Asthma Immunol 88: 478-487, 2002

9. Makino T: Pharmacological properties of Gyokuheifusan, a traditional Kampo medicinal formula. Yakugaku Zasshi 125 349-354, 2005 (In Japanese).

10. Yang SH and Yu CL: Antiinflammatory effects of Bu-zhong-yi-qi-tang in patients with perennial allergic rhinitis J Ethnopharmacol 115: 104-109, 2008.

11. Yang SH, Yu CL, Chen YL, Chiao SL and Chen ML: Traditional Chinese medicine, Xin-yi-san, reduces nasal symptoms of patients with perennial allergic rhinitis by its diverse immunomodulatory effects. Int Immunopharmacol 10: 951-958, 2010.

12. Wei Y, Lyu Y, Li M, Luo Q, Sun J, Liu F, Lin Y, Chen M, Nurahmat M, Abduwaki M and Dong J: Comparison of effect of granules and herbs of Bu-Shen-Yi-Qi-Tang on airway inflammation in asthmatic mice. Chin Med J (Engl) 127: 3957-3962, 2014.

13. Chen HY, Lin YH, Huang JW and Chen YC: Chinese herbal medicine network and core treatments for allergic skin diseases: Implications from a nationwide database. J Ethnopharmacol 168 260-267, 2015

14. Yamasaki H: Pharmacology of sinomenine, an anti-rheumatic alkaloid from Sinomenium acutum. Acta medica Okayama 30 $1-20,1976$.

15. Lodge D, Headley PM, Duggan AW and Biscoe TJ: The effects of morphine, etorphine and sinomenine on the chemical sensitivity and synaptic responses of Renshaw cells and other spinal neurones in the rat. Eur J Pharmacol 26: 277-284, 1974

16. Lee SS, Won TB, Kim JW, Rhee CS, Lee CH, Hong SC and Min YG: Effects of dexamethasone on the expression of transforming growth factor-beta in the mouse model of allergic rhinitis. Laryngoscope 117: 1323-1328, 2007.

17. Mo JH, Kang EK, Quan SH, Rhee CS, Lee CH and Kim DY: Anti-tumor necrosis factor-alpha treatment reduces allergic responses in an allergic rhinitis mouse model. Allergy 66 279-286, 2011.

18. Feng H, Yamaki K, Takano H, Inoue K, Yanagisawa R and Yoshino S: Suppression of Th1 and Th2 immune responses in mice by Sinomenine, an alkaloid extracted from the chinese medicinal plant Sinomenium acutum. Planta Med 72: $1383-1388,2006$

19. Okano M, Nishizaki K, Abe M, Wang MM, Yoshino T, Satoskar AR, Masuda Y and Harn DA Jr: Strain-dependent induction of allergic rhinitis without adjuvant in mice. Allergy 54: 593-601, 1999.

20. Livak KJ and Schmittgen TD: Analysis of relative gene expression data using real-time quantitative PCR and the 2(-Delta Delta C(T)) Method. Methods 25: 402-408, 2001.
21. Stokes JR, Romero FA Jr, Allan RJ, Phillips PG, Hackman F, Misfeldt J and Casale TB: The effects of an $\mathrm{H} 3$ receptor antagonist (PF-03654746) with fexofenadine on reducing allergic rhinitis symptoms. J Allergy Clin Immunol 129: 409-412, 412. e1-2, 2012.

22. Eliashar R and Levi-Schaffer F: The role of the eosinophil in nasal diseases. Curr Opin Otolaryngol Head Neck Surg 13: 171-175, 2005.

23. Skoner DP, Lee L, Doyle WJ, Boehm S and Fireman P: Nasal physiology and inflammatory mediators during natural pollen exposure. Ann Allergy 65: 206-210, 1990.

24. Rasp G, Thomas PA and Bujía J: Eosinophil inflammation of the nasal mucosa in allergic and non-allergic rhinitis measured by eosinophil cationic protein levels in native nasal fluid and serum. Clin Exp Allergy 24: 1151-1156, 1994.

25. Wilson SJ, Lau L and Howarth PH: Inflammatory mediators in naturally occurring rhinitis. Clin Exp Allergy 28: 220-227, 1998.

26. Liu L, Resch K and Kaever V: Inhibition of lymphocyte proliferation by the anti-arthritic drug sinomenine. Int J Immunopharmacol 16: 685-691, 1994

27. Hojo H, Kondo $\mathrm{Y}$, Umeda $\mathrm{H}$, Tahira $\mathrm{T}$ and Hashimoto $\mathrm{Y}$ : Effect of sinomenine on antibody responses in mice. J Immunopharmacol 7: 33-42, 1985.

28. Kim HM, Moon PD, Chae HJ, Kim HR, Chung JG, Kim JJ and Lee EJ: The stem of Sinomenium acutum inhibits mast cell-mediated anaphylactic reactions and tumor necrosis factor-alpha production from rat peritoneal mast cells. J Ethnopharmacol 70: $135-141,2000$.

29. Wang Y, Ma D, Jie Y, Wu Y and Pan Z: Sinomenine can prolong high-risk corneal graft survival in a rat model. Immunotherapy 4 581-586, 2012

30. Oh YC, Kang OH, Choi JG, Brice OO, Lee YS, Keum JH, Kim SB, Shin DW, Ma J, Jeong GH and Kwon DY: Anti-allergic effects of sinomenine by inhibition of prostaglandin $\mathrm{D}_{2}$ and leukotriene $\mathrm{C}_{4}$ in mouse bone marrow-derived mast cells. Immunopharmacol Immunotoxicol 33: 266-270, 2011.

31. Shu L, Yin W, Zhang J, Tang B, Kang YX, Ding F and Hua ZC: Sinomenine inhibits primary $\mathrm{CD} 4^{+} \mathrm{T}$-cell proliferation via apoptosis. Cell Biol Int 31: 784-789, 2007.

32. Miyata M, Hatsushika K, Ando T, Shimokawa N, Ohnuma Y, Katoh R, Suto H, Ogawa H, Masuyama K and Nakao A: Mast cell regulation of epithelial TSLP expression plays an important role in the development of allergic rhinitis. Eur J Immunol 38: 1487-1492, 2008

33. Cheng Y, Zhang J, Hou W, Wang D, Li F, Zhang Y and Yuan F: Immunoregulatory effects of sinomenine on the T-bet/GATA-3 ratio and Th1/Th2 cytokine balance in the treatment of mesangial proliferative nephritis. Int Immunopharmacol 9: 894-899, 2009.

34. Xu G, Mou Z, Jiang H, Cheng L, Shi J, Xu R, Oh Y and Li H: A possible role of $\mathrm{CD} 4{ }^{+} \mathrm{CD} 25^{+} \mathrm{T}$ cells as well as transcription factor Foxp3 in the dysregulation of allergic rhinitis. Laryngoscope 117: 876-880, 2007

35. Lee SM, Gao B, Dahl M, Calhoun K and Fang D: Decreased FoxP3 gene expression in the nasal secretions from patients with allergic rhinitis. Otolaryngol Head Neck Surg 140: 197-201, 2009.

36. Malmhäll C, Bossios A, Pullerits T and Lötvall J: Effects of pollen and nasal glucocorticoid on FOXP3 ${ }^{+}$, GATA- $3^{+}$and T-bet ${ }^{+}$ cells in allergic rhinitis. Allergy 62: 1007-1013, 2007.

37. Dardalhon V, Awasthi A, Kwon H, Galileos G, Gao W, Sobel RA, Mitsdoerffer M, Strom TB, Elyaman W, Ho IC, et al: IL-4 inhibits TGF-beta-induced Foxp3 ${ }^{+} \mathrm{T}$ cells and, together with TGF-beta, generates IL-9+ IL-10+ Foxp3(-) effector T cells. Nat Immunol 9: 1347-1355, 2008

38. Dardalhon V, Korn T, Kuchroo VK and Anderson AC: Role of Th1 and Th17 cells in organ-specific autoimmunity. J Autoimmun 31 252-256, 2008

39. Taylor A, Verhagen J, Blaser K, Akdis M and Akdis CA: Mechanisms of immune suppression by interleukin-10 and transforming growth factor-beta: The role of $\mathrm{T}$ regulatory cells. Immunology 117: 433-442, 2006. 